\title{
Safety Patient: In Search of Autonomy
}

\author{
Eloisa Gabriela Linke, Tiago Calvis Siebert ${ }^{1}$, Priscilla Dal Prá Campos ${ }^{2}$, Daniela Bianchi Garcia ${ }^{2}$ and \\ Elaine Rossi Ribeiro ${ }^{3 *}$ \\ ${ }^{1}$ Medical students at Pequeno Príncipe Faculties, Brazil
}

${ }^{2}$ Students of the Master's Degree Program in Health Sciences Teaching, Brazil

${ }^{3}$ Faculty researcher at Pequeno Príncipe Faculties, Brazil

\begin{abstract}
Introduction: The participation of patients in their own safety in health services contributes to making them the protagonist of their care. Since the patient is a key player when it comes to health safety, involving him in this process is a task that must be done through coordinated efforts between institutions and health professionals. This discussion guides the research question: how can patients seek their own safety with autonomy in health services?
\end{abstract}

Objective: to identify the knowledge built by the patient in their performance regarding their own safety in health services, recognizing the main measures used and difficulties in this process.

Methodology: It is a descriptive research with a quantitative approach, carried out in a reference hospital in Paraná, Brazil. Results: Fifty adult patients from a general care hospital participated in the study, observing little knowledge about patient safety measures.

Conclusion: The factors that contribute to the patient's participation in their own safety in health services, in search of autonomy are the following: patient information and education, encouraging their participation, the patient's own initiative, valuing individual concerns and the effective doctor-patient relationship.

KEYWORDS: Patient safety; Patient participation; Health care

\section{INTRODUCTION}

Patient safety is defined as "reducing to an acceptable minimum the risk of unnecessary harm associated with healthcare" [1]. Health care can expose the patient to various types of risk situations in the hospital environment, which can cause damage to their health. Two thousand years ago, Hippocrates highlighted in his oath the duty to apply treatments to help patients according to the doctor's skill and capacity, and never use them to cause harm or harm [2].

The Medical Ethics Code itself is inspired by this oath to, in Article 1 of Chapter III, state that the physician is prohibited from harming the patient by action or omission, characterized as malpractice or negligence [3]. It is observed that both the oath and article emphasize the importance of the physician in the care of the patient's health. However, the patient himself is a key player in and for health care and it is increasingly being valued, including by international institutions such as the WHO.

The health services, when they seek qualification, initiatives have been developed to improve work processes, one of which is the World Alliance for Patient Safety, defined by the World Health Organization in 2004 [4]. It proposes the adoption of measures to reduce risk and adverse events related to health care. Thus, the International Patient Safety Goals include correct patient

\begin{tabular}{|l|l|}
$\begin{array}{l}\text { Quick Response Code: } \\
\text { Pddress for correspondence: Elaine Rossi Ribeiro, Faculty researcher at Pequeno } \\
\text { Príncipe Faculties, Brazil }\end{array}$ \\
\cline { 2 - 2 } & $\begin{array}{l}\text { Received: July 19,2021 Published: July 27, } 2021 \\
\text { How to cite this article: Eloisa Gabriela L, Tiago Calvis S, Priscilla Dal Prá C, Daniela Bianchi } \\
\text { G, Elaine Rossi R. Safety Patient: In Search of Autonomy. 2021- 3(4) OAJBS.ID.000308. DOI: } \\
\text { 10.38125/OAJBS.000308 }\end{array}$ \\
\hline
\end{tabular}


identification, effective communication, high surveillance drug safety, safe surgery, the reduction of the risk of infections associated with healthcare and prevention of damage resulting from falls [5].

In this scenario, where health institutions and professionals seek to improve this theme, with the support of ministerial programs and projects, there is still a lack of voice for the patient. Thus, in Brazil, the Patient for Patient Safety Program was launched, which became essential to include the role of the patient in the intervention proposals [1].

In the current context, there are still difficulties for the inclusion and accountability of the patient in the care of their own safety. This situation causes damage to their own health, and even cause irreversible sequels [6]. Therefore, advances in the promotion of patient safety and in society's education levels increasingly contribute to patients demanding increasingly and collaborating so that health care is provided with quality and can reflect the coordinated effort idealized by the program quoted.

Given this scenario, it is important to understand the level of understanding of patients' cognition and their role in this process. Through person-centered care, the empowerment and autonomy of the patient to be the protagonist of their own care is guaranteed. Therefore, from this study, we seek to answer the following research question: does the construction of knowledge by patients about their role as protagonists in their own safety contribute to the development of their autonomy in health care? Based on this premise, this research identifies the knowledge built by the patient in their performance regarding their own safety in health services, recognizing the main measures used and the difficulties of this process.

\section{METHODOLOGY}

This study is a descriptive research with a quantitative approach. The research site was a general hospital in Paraná Brazil, and the participants were 50 adult patients. To reach this number of 50 participants, a sample calculation was performed by considering the number of individuals in the sample $\mathrm{Za} / 2=$ critical value of the confidence level.

The inclusion criteria adopted were patients between the ages of 18 and 80 , without distinction of sex or color, admitted to wards or rooms for clinical or surgical reasons for at least $24 \mathrm{~h}$ to have the opportunity to learn about safety practices. Patients hospitalized in the ICU were also excluded, in addition to those who could not answer the questionnaire due to physical or mental conditions.

Participants' knowledge of safety measures, based on the Six International Patient Safety Goals proposed by the World Health Organization, was addressed through the application of a closed questionnaire. The collected data are organized in a table and submitted to simple descriptive analysis by analyzing the frequency of responses using the Excel $®$ software.

\section{RESULTS}

This research involved participating 50 people approached in the second half of 2019. There was a predominance of females and regarding age, patients have an older age profile, with an average of 52.74 years, with $88 \%$ of hospitalization for acts surgical procedures. Regarding education, 32\% have incomplete primary education and only $10 \%$ have higher education.

Regarding the interviewees' knowledge about the Patient Safety measures proposed by the health systems, $66 \%$ of the patients declared that they knew about the measures related to the program. They pointed out that the direct explanation by health professionals is the main means of information about their safety, followed using the guidelines provided by the informational posters available in the services. Also, respondents reported that the main guidance reinforced by the institutions is proper hand hygiene.

Considering communication as one of the patient safety goals, participants report that they seek to understand the treatments and procedures they are submitted to with health professionals, and only $24 \%$ of patients did not seek information about the procedures when still had doubts. In relation to informing the physician about the use of continuous medications, $76 \%$ of respondents in general reported informing all medications in use during the consultation. However, $20 \%$ of respondents reported only the medications they considered important and $4 \%$ did not report any medication in use.

Regarding the quality of communication with health professionals about the service, 20\% understood everything the professionals said, $44 \%$ understood a lot, $10 \%$ understood partially, $22 \%$ understood little and $4 \%$ did not understand what the professionals said. Questioning about measures taken by professionals in relation to care and considered wrong by patients, only $20 \%$ of patients always or frequently questioned professionals in these cases, $42 \%$ sometimes and the rest rarely or never. As for legal guardians, 70\% always or frequently questioned these errors, $14 \%$ sometimes and $16 \%$ rarely or never.

Asked about the goal of safe surgery, where name confirmation before surgery is an important part of this process, $41 \%$ of total respondents reported that they confirmed their name in the operating room, $8 \%$ said they did not ask, and $51 \%$ of adult patients did not participate in surgery. About hand hygiene, only $14 \%$ of patients claimed to always wash their hands and $44 \%$ frequently. Still, $16 \%$ of patients rarely them sometimes, $22 \%$ sanitize and $4 \%$ declared that they had not done hand hygiene during the hospitalization period, this period being longer than two days.

In the prevention of infections related to health services through hand hygiene before contacting the patient or performing procedures, the interviewees showed attention to the professionals' conduct. It was found that $64 \%$ of patients observed that professionals performed hand hygiene every time, not requiring intervention. Still, among patients, $24 \%$ report not having charged once when they realize that professionals make this mistake, $4 \%$ charge sometimes and only $8 \%$ always charges correct hand hygiene when they see that it does not occur.

Data on the prevention of falls, in which the orientation is that the patient does not go down alone or using a bed ladder, reveal that $30 \%$ always ask for help, 30\% frequently, 20\% sometimes or rarely, and $20 \%$ never. Regarding changing position in bed to prevent pressure injury, $62 \%$ change position whenever they feel discomfort, $24 \%$ sometimes change position, $6 \%$ need to ask for help to change position and $8 \%$ cannot change position and does not ask for help for that.

\section{DISCUSSION}

This research identified the knowledge built by a group of patients regarding patient safety measures within the hospital environment, demonstrating the importance of their role as a protagonist in this process.

The characteristics of the hospital environment play a fundamental role in the inclusion of the patient in the adoption and 
practice of safety measures. None of the patients reported learning about safety from posters and pamphlets, which may be related to the means of information used by the hospital, which has only a few posters near the sinks that provide guidance on hand washing. The importance of using different types of information is perceived, in addition to effective communication by professionals.

The third Patient Safety Goal advocates the rational reasonable of medication to qualify health care. The data analyzed in this research corroborate the study by Oenning et al. [7] in which patients' knowledge about prescribed drugs was surveyed. By analyzing information about the name of the medication, dose, indication, frequency of use, duration of treatment, adverse effects, among others, after the medical consultation, the authors concluded that most respondents do not have a good level of information for medication administration, and $64.4 \%$ had knowledge considered insufficient about prescribing medications.

The patient's responsibility for their treatment with the involvement of professionals and the management system includes the active participation of users with knowledge about the correct use of these [7]. This author also highlights the importance of multidisciplinary care, as the participation of the pharmacist and the nursing team improves guidance on the correct use of medications. Multidisciplinary care contributes to better patient information and development of the autonomy of their care related to the correct use of medication.

A study published by Barel [8], related the knowledge of patients undergoing maxillofacial surgery and anxiety in the preoperative period. Although it is not a surgery performed by any interviewee in this study, many patients underwent invasive procedures during hospitalization about which they did not have adequate information. This study observed that there is a direct relationship between knowledge of the procedures that are performed and the level of anxiety of patients. It is concluded that there is a need to educate patients about the procedures and care involving them, contributing to the control of anxiety about their health and to the improvement of the perception of self-care.

The literature review published by Ugarte and Acioly discusses the exercise of patient autonomy regarding decisions related to their treatment [9]. For the authors, it is impossible to have autonomy if you do not understand the situation from its objectives to its consequences. Although some claim that, as laypeople, patients do not have sufficient understanding to comprehend the procedures proposed by physicians, the authors argue that patients are capable of understanding the points deemed important and significant by the physician, provided a welcoming environment is provided, with encouragement for discussion and knowledge of the patient's concerns.

The Federal Pharmacy Council maintains that patients who know the names and doses of their medications, why they should be used, and how they should be taken are in a position to help reduce the possibility of errors occurring [10]. Such errors can be fatal, as some medications have a greater potential to cause serious harm to patients when their use fails. Therefore, it is essential to have companions during hospital stays, as not all patients remember the medications and their doses. This observation corroborates with the data from this research, in which $24 \%$ of respondents reported talking about only some or none of the medications they used, the main reason being forgetting their names and excluding herbal and allopathic medications.
Regarding effective communication with professionals, little understanding of what professionals say was observed, mainly due to the use of scientific terms and communication between professionals and students without the direct inclusion of patients. For effective communication to occur, it is necessary to use a clear and objective language, avoiding technical terminology, and always seeking to provide complete and accurate information to patients and provide opportunities to clarify doubts that may arise [11].

A study published by Pereira et al. [12] interviewed 94 patients assisted by the Family Health Strategy in a unit in Ceará_Br, regarding their knowledge about their drug treatment after medical consultation. Of these, $82 \%$ said they had been informed about the dosage, $78 \%$ about the duration of treatment and $63 \%$ about the therapeutic purposes. From this study, it was concluded that the improvement of the communication process between the doctor and the patient can impact the patient's low adherence to the prescribed treatment. Communication cannot be a barrier, but rather open space for welcoming and establishing an interpersonal relationship between patient and professional, acting as a humanizing factor. Likewise, to ensure the best safety for the patient, it is necessary for the doctor-patient communication to be effective, as well as between professionals [13].

Reason proposes the Swiss Cheese Model, which explains why even in complex systems there can be failures [14]. In the model, any component of an organization can be considered a slice of cheese (identification, prescription, procedures) and these slices have their flaws. If these faults line up, there will be no barriers to prevent an accident. With this logic, it is important to be aware that both the health professional and the patient must be part of the work process to avoid mistakes, such as an extra slice of cheese, and questioning what is being done by the professional is a means to that end.

In 2008, WHO launched a campaign to ensure patient safety in the operating room. For this, each hospital should have its checklist to be followed, thus ensuring a reduction in mortality and sequelae to patients [15]. It is necessary to involve the entire team during the check, so that everyone respects each item on the list and is aware that its effective implementation will save lives. A systematic review of the impacts and implementation of surgical checklists showed that its use can prevent errors and operative complications, reducing post-surgical complications and mortality rates, in addition to providing greater safety for the patient and improve communication with care team performed frequently [15]. In order for care to be safer, it is necessary to build a culture of patient safety, in which professionals and services share practices, values, attitudes and behaviors to reduce harm and promote safe care.

As for the main ways of washing hands, it is pointed out that the most used products are alcohol, soap and water. Participants highlighted the reinforcement that professionals always make so that they perform hand hygiene with alcohol more frequently. But it was observed that the frequency of hand hygiene is low and that alcohol was not available in the hospital near their beds, which can make this practice more difficult, as $42 \%$ of them reported washing their hands sometimes, rarely or never. Another factor that can impact the frequency of hand hygiene of these patients is the motor limitation, as they spend most of their time in bed, without contact with other objects or people.

Another important point is hand hygiene of professionals who come into contact with patients. This reinforces the need 
to encourage the collaboration of patients, family members, companions and visitors for hand hygiene, asking professionals to sanitize their hands before performing their activities. Also, according to Anvisa [6], the effective involvement of patients and their support network helps in adherence to hand hygiene practices among health professionals, as patients play a vigilant and inspecting role for such measures. Thus, patient education is part of the strategies to promote hand hygiene in health services [6].

The researchers observed the fear that some interviewees have in questioning attitudes they consider wrong or inappropriate on behalf of professionals. They report fearing retaliation in the service if they confront the professionals' actions, and some respondents were concerned that their negative responses to the professionals might be exposed to them and suffer reprisals. These observations demonstrate a feeling of submission on behalf of some patients in relation to their care, which can be harmful to their autonomy and also to the quality of services. In 1972, Veatch proposed the contractualist model of the doctor-patient relationship, preserving the effective knowledge of the doctor combined with the active participation of the patient, with an exchange of information and commitment on both sides [16]. According to these authors, when, at present, patients have broad access to information technologies, both parties need to be valued and active participants in decisionmaking. Thus, the fears presented by the patients in this study, which show a relationship of submission to the professionals, would be minimized, making them protagonists and important contributors to their own care in a warm and balanced relationship.

The fact that most patients do not find it relevant to ask for help with mobility shows how worrying the situation is. However, this lack of care can lead to worsening of conditions, as falls not only increase the length of stay of patients, but also the cost of treatment for the service.

Based on this research, it can be concluded that incorporating the patient as a protagonist of their autonomous care is a challenge for health services. Encouraging the patient's active participation in health care makes it a useful tool to qualify health services. It is believed that a participating patient who is critical of the safety measures for which he is responsible, will be able to develop greater autonomy regarding his care and health.

Knowing the relationship of patients with Patient Safety practices in health services, as well as the main measures used and the difficulties involved in this process, some of the main factors in encouraging the effective participation of patients and their support network were identified: information and patient education; encouraging patient participation by institutions; the patient's own initiative; appreciation of individual concerns and good doctor-patient relationship.

\section{CONCLUSION}

The study allowed us to identify the knowledge constructed by patients regarding their participation in their own safety. It is true that some difficulties are encountered, such as the submissive posture of patients and the difficulty of communicating with professionals, for example, and there is still a lot to be done. However, from the results and data analysis of this research, it can be concluded that patient information and education, encouraging patient participation, patient's own initiative, valuing individual concerns, and an appropriate doctor-patient relationship are factors that constitute patient empowerment to promote their own safety in healthcare. Thus, the possibilities and challenges for constructing knowledge and the development of autonomy in selfcare is revealed.

\section{REFERENCES}

1. AllegranzI B (2007) The first global patient safety challenge "clean care is safer care": From launch to current progress and achievements. J Hosp Infect London 65: 115-123.

2. Rezende JMÀ (2009) Sombra do plátano: crônicas de história da medicina. São Paulo, Brazil.

3. (2019) Conselho Federal de Medicina. Resolução CFM №1931/2009. Código de Ética Médica. Brasília.

4. (2007) World Health Organization (WHO) Word alliance for patient safety. Geneva, Switzerland.

5. (2014) Joint commission international. Padrões de Acreditação da Joint Comission International para Hospitais. $5^{\text {th }}$ edn. Illinois: Joint Commission Resources.

6. Melo FO, Caveião C (2002-2015) Erros de medicação em hospitais e a farmacovigilância na segurança do paciente.

7. Oenning D, Oliveira BV, Blatt CR (2011) Conhecimento dos pacientes sobre os medicamentos prescritos após consulta médica e dispensação. Cien. Saúde Colet, Rio de Janeiro16(7): 3277-3283.

8. BareL PS (2018) Ansiedade e conhecimento de pacientes submetidos a cirurgia ortognática no pré-operatório. Rev Bras Enferm Brasília 71(5): 2206-2211.

9. Ugarte N, Acioly Ma (2018) Princípio da autonomia no Brasil: discutir é preciso. Rev Col Bras Cir Rio de Janeiro 71(5): 2206-2211.

10. Anacleto TA (2019) Farmácia hospitalar: Erros de medicação. Pharm.

11. Silva T de O (2016) Envolvimento do paciente na segurança do cuidado: revisão integrativa. Rev Eletrônica Enferm Goiás.

12. Pereira MV (2016) Grau de conhecimento dos pacientes sobre o tratamento: estratégia para uso racional de medicamentos. J Health NPEPS, Tantará da Serra 1(1): 31-39.

13. Bertachil LA (2012) Comunicação terapêutica como fator de humanização da Atenção Primária. Revista o Mundo da Saúde, São Paulo 36(1): 507-520.

14. Reason J (2000) Human error: models and management. BMJ Londres 320(7237): 768-770.

15. Alpendre FT (2017) Safe surgery: validation of pre and postoperative checklists. Rev Lat Am Enfermagem, Ribeirão Preto 25: e2907.

16. Rocha BV (2011) Relação médico-paciente. Rev Med Res Curitiba 13(2): 114-118. 